\title{
BMJ Open Cross-sectional study of cognitive stress appraisal and related factors among workers in metropolitan areas of Japan
}

\author{
Natsuka Tohmiya, ${ }^{1}$ Etsuko Tadaka, ${ }^{2}$ Azusa Arimoto $^{2}$
}

To cite: Tohmiya N, Tadaka E, Arimoto A. Cross-sectional study of cognitive stress appraisal and related factors among workers in metropolitan areas of Japan. BMJ Open 2018;8:e019404. doi:10.1136/ bmjopen-2017-019404

- Prepublication history for this paper is available online. To view these files, please visit the journal online (http://dx.doi org/10.1136/bmjopen-2017019404).

Received 5 September 2017 Revised 9 March 2018 Accepted 20 April 2018
Check for updates

${ }^{1}$ Public Health Promotion Division, Setagaya District Administration Offices,

Setagaya, Japan

${ }^{2}$ Department of Community Health Nursing, Guraduate School of Medicine, Yokohama City University, Yokohama, Japan

Correspondence to

Natsuka Tohmiya;

natsuka.dct.ft@gmail.com

\section{ABSTRACT}

Objective Stress has major socioeconomic implications for all spheres of employment. It is a trigger for depression, and affects absenteeism, turnover, productivity, morale and suicide. Positive or negative cognitive stress appraisal can be a self-care strategy that affects workers' ability to cope with stress. This study examined cognitive stress appraisal among workers and identified related individual and environmental factors.

Design Cross-sectional study using self-administered postal questionnaires.

Setting Companies located in two metropolitan areas of Japan (Tokyo and Kanagawa prefectures).

Participants 2311 employees of 48 companies in metropolitan areas in Japan. In total, 341 questionnaires were returned (response rate: 14.8\%), 337 of which were suitable for analysis (effective response rate: $98.8 \%$ ).

Primary measures Cognitive stress appraisal was assessed using the Japanese version of the Perceived Stress Scale (PSS). Potential variables related to stress appraisal included demographic, individual and environmental factors. Multiple regression analysis was used to identify factors related to cognitive stress appraisal.

Results Participants' mean \pm SD age was $42.8 \pm 11.7$ years, and two-thirds were male. The mean \pm SDPSS score was $25.8 \pm 6$.2. The multiple regression analysis controlled for age, sex and depression showed that those with poorer economic status $(\beta=0.171, p<0.001)$, lower electronic health (eHealth) literacy $(\beta=-0.113, p=0.012)$, higher traditional organisational climate $(\beta=0.131, p=0.004)$ and lower perceived social support $(\beta=-0.205, p<0.001)$ experienced significantly higher levels of negatively perceived stress.

Conclusions The results show individual and environmental factors related to cognitive stress appraisal among workers. An effective strategy to improve mental health among workers may involve an interprofessional approach by public health nurses and health practitioners that includes enhanced self-coping skills using individual workers' eHealth literacy, improvement of organisational climates in workplaces and community-based social support.

\section{INTRODUCTION}

Depression is a common psychiatric disorder, affecting about 350 million people worldwide and is a major contributor to the overall global burden of disease. ${ }^{1}$ In Japan, depression is estimated to have affected up to

\section{Strengths and limitations of this study}

This study is the first to examine individual and environmental factors related to cognitive stress appraisal among healthy workers.

- We simultaneously examined electronic health literacy, multidimensional perceived social support and traditional organisational climates.

- This study used a cross-sectional design, and could not identify causal relationships between cognitive stress appraisal and related factors.

- The target population of this study was limited to metropolitan areas in Japan.

1.116 million people in $2015 .^{2}$ Depression is different from usual mood fluctuations and short-lived emotional responses to challenges in everyday life. Especially when long lasting and with moderate or severe intensity, depression may become a serious health condition. In particular, depression caused by occupational stress result in increasing rates of longterm illness and absence from work among workers. ${ }^{3}$ WHO's Comprehensive Mental Health Action Plan 2013-2020 adopted by the 66th World Health Assembly ${ }^{4}$ argues that determinants of mental health and psychiatric disorders include individual attributes and social, cultural, economic, political and environmental factors for protecting workers' health. ${ }^{5}$ Mental illnesses are associated with a substantial deterioration in individual quality of life, and economic loss in the community and workplace. ${ }^{56}$ Therefore, primary prevention of depressive disorders is important nationally and internationally, as well as for individuals.

Stress has major socioeconomic implications for all spheres of employment. It is a trigger for depression and affects absenteeism, turnover, productivity, morale and suicide. ${ }^{7-9}$ In Japan, the number of employees who applied for industrial accident compensation insurance for mental disorders because of stress has increased in recent 
years. ${ }^{10}$ There was 1515 applications in 2015 , which was up from 1272 in $2011 .^{11}$ The proportion of workers experiencing anxiety, distress and work stress has progressively increased since 1982, and is now estimated at $60 \% .{ }^{12}$ In this context, the Japanese government launched 'The Stress Check Program' in 2015, a new occupational health policy to screen for workers experiencing high psychosocial stress. ${ }^{13}$ The law mandates use of the Stress Check Program and its guidelines at least once each year in all workplaces in Japan with 50 or more employees. The programme and guidelines recommend individual checks for perceived stress, and sets out four principles of care in the workplace: (1) self-care, (2) line-care, (3) health practitioners' care in the workplace and (4) health practitioners' care in the community.

Cognitive stress appraisal is a self-care strategy based on individuals' evaluation of how they perceive stressors. In primary appraisal, an individual's evaluations are divided into 'threat' and 'challenge'; threat describes anticipated harm/loss, and challenge describes a threat that can be met or overcome. ${ }^{1415}$ The cognitive appraisal of something as a 'threat' or 'challenge' can affect mental health. ${ }^{15} 16$ The stress response and stress coping following cognitive appraisal differ among individuals, even in response to the same stressors. ${ }^{17}$ For example, people making a positive cognitive appraisal may perceive stress as a challenging health issue to be resolved, and set themselves challenging goals. ${ }^{14} 15$ Those making a negative cognitive appraisal may view the same issue as a health threat, and believe that resolving the issue is beyond their abilities. Positive or negative cognitive stress appraisal can therefore be an important mental health concept to improve stress-coping skills and control stress among workers. For individuals, positive cognitive appraisal contributes to prevention of depression, thereby improving quality of life. At the societal level, this is important in controlling the escalation of medical costs and increasing corporate and community-wide productivity.

The Perceived Stress Scale (PSS) measures the degree to which situations are cognitively appraised as stressful. ${ }^{18}$ Cohen explained the PSS as a measure of the degree to which situations in one's life are appraised as stressful. PSS items were designed to capture how unpredictable, uncontrollable and overloaded respondents perceive their lives. These issues have been repeatedly found to be central components of the experience of stress. In addition, stressful life events influence disease risk through an individual's perceptions of stress and negative affect. ${ }^{18}$ Cohen also noted that the PSS can be used to determine whether 'appraised' stress is an aetiological (or risk) factor in behavioural disorders or disease ${ }^{18} 19$ Therefore, we considered that the PSS can continuously measure negative cognitive stress appraisal. Previous studies have measured cognitive stress appraisal using the PSS and investigated related factors with students, ${ }^{20-24}$ medical professionals $^{2526}$ and patients with chronic diseases. ${ }^{27-30}$ However, the scale has not previously been used with healthy adult workers in a range of employment types.
Previous studies clarified various individual factors related to the PSS, but these varied for different participants. Some studies examined the physical and psychological health conditions among students or conditions in particular populations (eg, adults with a disease or pregnant women). ${ }^{28} 3132$ Other studies examined lifestyle factors among students, pregnant women and medical professionals $^{263334}$, job stress among medical professionals ${ }^{253536}$, stressors and coping in adult survivors of suicide and pregnant women ${ }^{3137}$, and health literacy in African-American adults. ${ }^{38}$ However, there is limited information about the relationship between cognitive stress appraisal and individual and environmental factors (eg, work environment and available social support) among adult workers. ${ }^{39}$

This study aimed to examine cognitive stress appraisal among workers and identify associated individual and environmental factors. The findings may contribute to minimising the effect of factors associated with an increased risk for depression, and contribute to promoting individual self-care and improving workplace environments to promote mental health among workers. Furthermore, the findings may be useful for public health nurses and health practitioners at worksites engaged in primary prevention of mental health disorders among workers.

\section{METHODS}

\section{Participants and sampling}

Study participants were employees of companies located in metropolitan areas of Japan. The inclusion criterion was employees aged $18-64$ years. The age of 64 years is the upper limit for consideration of retirement and re-employment under the Japanese Law Concerning Stabilization of Employment of Older Persons, and 18 years is the youngest age for employment immediately after graduating high school in Japan.

This study used a cross-sectional design with self-administered postal questionnaires. Data were collected from employees of companies registered in the Japan Company Handbook 2016 across two metropolitan areas of Japan (Tokyo and Kanagawa prefectures). We stratified companies by size and type of industry, and selected companies randomly within that stratification; 361 of a total 2026 companies were selected $(17.8 \%)$. The questionnaire did not collect details about company name, number of employees and type of industry to safeguard participant anonymity.

\section{Data collection}

Out of 361,48 companies agreed to participate in this study. Before sending the questionnaires to each company, we identified the relevant sample size from company administrators. In total, 2311 questionnaires were mailed to the 48 companies. Of these, 341 questionnaires were returned (response rate: 14.8\%). Potential participants (all employees of the participating companies) were invited to complete the questionnaire anonymously on a voluntary basis, between 1 October 2016 and 
9 December 2016. Participant anonymity was maintained throughout data collection as the questionnaires did not collecting any identifying information. In addition, participants returned completed questionnaires by mail to the researchers themselves. Returning a completed questionnaire was considered to indicate provision of informed consent.

\section{Instruments}

Dependent variable: cognitive stress appraisal

The dependent variable was cognitive stress appraisal, which was determined using the Japanese version of the PSS. $^{40} 41$ The PSS comprises 14 items and includes questions such as, 'In the last month, how often have you been upset because of something that happened unexpectedly?' and 'In the last month, how often have you felt that you were unable to control the important things in your life?' Responses were coded for scoring as never $=0$, almost never $=1$, sometimes $=2$, fairly often $=3$ and very often $=4$. Possible total scores ranged from 0 to 56 , with higher scores indicating higher levels of negative cognitive stress appraisal. All 14 items in the Japanese version of the scale are highly intercorrelated (Cronbach's alpha $=0.74$ ).

\section{Demographic characteristics}

Participants' demographic characteristics included age, sex (male=1, female=2), marital status (unmarried and divorced/widowed=1, married $=2$ ), household membership (live alone $=1$, spouse $=2$, spouse and children $=3$, parents $=4$, others $=5$ ), educational status (junior high school/high school=1, vocational college/Junior college $=2$, college or university/graduate school $=3$ ), employment status (fulltime $=1$, part time $=2$, others $=3$ ), economic status (sufficient $=1$, slightly sufficient $=2$, slightly insufficient $=3$, insufficient $=4$ ) and depression. Items were based on standard questions generally used in previous studies involving workers and items used in a recent national survey for workers.

Depression was measured using the Japanese version of the Center for Epidemiologic Studies Depression Scale (CES-D) ${ }^{42}{ }^{43}$ which comprises 20 items. Each item is measured on a four-point Likert-type scale from 0 to 3 . Total scores range from 0 to 60 , with higher scores indicating greater levels of depression. CES-D scores above 16 indicate a depressive state. The CES-D was developed for use in epidemiological studies of depressive symptomatology in the general population. ${ }^{42}{ }^{43} \mathrm{~A}$ specific group with a higher mean score may be interpreted to be at risk for a depressive state or in need of intervention. ${ }^{43}$ Cognitive stress appraisal is affected by participants' mental condition at that particular time, which includes depression. The psychometric properties of the CES-D have been investigated, and the scale showed high internal consistency, acceptable test-retest stability, excellent concurrent validity for clinical and self-report criteria and substantial evidence of construct validity. When the CES-D was designed, the internal consistency was high in the general population $(0.77-0.87)$ and higher in the patient sample (0.85-0.92), and test-retest correlations were in the moderate range $(0.45-0.70)$. In addition, the CES-D showed moderate correlations with the Hamilton Clinician's Rating scale and the Raskin Rating scale (0.44-0.54) at admission. ${ }^{42}$

\section{Independent variables}

The conceptual framework of this study was to examine cognitive stress appraisal and identify related individual and environmental factors. According to Lazarus's theory, individual and environmental factors mutually affect the cognitive stress appraisal process. Therefore, we considered both individual and environmental factors to be important. Independent variables were selected based on previous studies. ${ }^{20-37}$

Individual factors included any disease currently under treatment (eg, cancer, diabetes), body mass index (BMI), self-rated health, physical complaints, physical demands, lifestyle, perceived health competence and electronic health (eHealth) literacy. BMI was calculated from self-reported weight and height. Self-rated health was measured on a four-point Likert-type scale from 1 (very poor) to 4 (very good).

Physical complaints were measured using the Brief Job Stress Questionnaire (BJSQ) ${ }^{44}$ The BJSQ is used in the Japan Stress Check Test by the Ministry of Health, Labour and Welfare, ${ }^{12}$ and can be easily used in the workplace. It comprises 57 items on 19 subscales, from which we drew 11 items (eg, 'I have felt dizzy' and 'I have experienced joint pains'). Each item was measured on a four-point Likert-type scale. Total scores ranged from 11 to 44, with higher scores indicating more frequent physical complaints. Physical demands were measured using the Job Content Questionnaire (JCQ), ${ }^{45}$ which comprises 45 items on 6 subscales. We used three items for physical exertion and two for isometric load. Items were measured on a five-point Likert-type scale. Total scores for physical exertion ranged from 3 to 15, and for isometric load from 2 to 10 , with higher scores indicating stronger physical demands/isometric load. The JCQ was developed based on the job demands-control model, and has been nationally standardised by occupation in several countries. ${ }^{45-47}$

Lifestyle was measured using seven items based on Breslow's good health habits. ${ }^{48}$ These items covered smoking, drinking alcohol, eating breakfast every day, physical activity, eating snacks after dinner, skipping breakfast, and sleeping and resting. Responses were coded for scoring as 'yes' or 'no'. Perceived health competence was measured using the Japanese version of the Perceived Health Competence Scale (PHCS) ${ }^{49}$ The PHCS comprises eight items measured on a five-point Likert-type scale. Total scores ranged from 8 to 40, with higher scores indicating higher perceived health competence. Perceived health competence is related to stress, ${ }^{50}$ and the PHCS was designed to assess efficacy and competence beliefs about personal health at an intermediate level of domain specificity. ${ }^{51}$ 
Finally, eHealth literacy was measured using the Japanese version of the eight-item eHealth Literacy Scale (eHEALS).$^{52}$ eHealth literacy is defined as the ability to seek, find, understand and appraise health information from electronic sources, and apply that knowledge in addressing or solving a health problem. ${ }^{53}$ Responses were assessed using a five-point Likert-type scale. Total scores ranged from 8 to 40 , with higher scores indicating greater eHealth literacy. In Japan, internet penetration in the studied age group is over $90 \% .^{55}$ eHEALS was developed to address the need to assess eHealth literacy for a range of populations and contexts. It is designed to provide a general estimate of consumer eHealth-related skills to inform clinical decision-making and health promotion planning for individuals or specific populations. ${ }^{54}$

\section{Environmental factors: organisational climate}

Organisational climate was measured using the 12-item Organisational Climate Scale ${ }^{56}$ which is divided into two six-item subscales: a tradition scale and an organisational environment scale. Responses were coded for scoring as yes $=2$ and no $=1$. The total possible scores ranged from 6 to 12 for each subscale. Higher scores on the tradition scale indicate a more mandatory, injunctive and feudalistic organisational climate. Higher scores on the organisational environment scale indicate a more flexible organisational system. A previous study showed that organisational climate may affect occupational stress. ${ }^{57}$ This scale measures organisational properties based on the model of healthy work organisations at the National Institute for Occupational Safety and Health of US Department of Labor. ${ }^{56}$

\section{Social support}

Social support was measured using the short version of the Multidimensional Scale of Perceived Social Support (MPSS) in Japanese, ${ }^{58} 59$ which comprises seven items. Responses were on a seven-point Likert-type scale, with lower scores indicating lower perceived social support. The MPSS specifically addresses the subjective assessment of social support adequacy, and was designed to assess perceptions of social support adequacy from three sources: family, friends and significant others. ${ }^{59}$

\section{Statistical analysis}

Means, SDs, frequencies and percentages were calculated for demographic characteristics, positive or negative cognitive stress appraisal (PSS scores), and individual and environmental factors. Univariate analysis using Spearman's correlation was used to examine correlations between the dependent and independent variables. A multiple regression analysis was then used to identify factors related to cognitive stress appraisal among workers, using all potentially significant predictors identified by the univariate analyses $(p<0.05)$. Multicollinearity of independent variables was considered via the forced entry (variable reduction) method. The multiple regression model included selected independent variables and all statistical analyses.
In the model, step 1 included the control variables, step 2 the demographic characteristics and step 3 the remaining predictors. Sex, age and depression were entered as control variables. A previous study reported high correlation between the PSS and the CES-D, but both scales still independently predicted symptomatology. ${ }^{18}$ Because the aim of this study was primary prevention of poor mental health, specifically depression, we assumed that depression was a covariate and treated it as a control variable. Of the 337 effective response, data were missing for; BMI $(\mathrm{n}=2,0.59 \%)$, self-rated health $(\mathrm{n}=14,4.15 \%)$, household membership ( $\mathrm{n}=3,0.89 \%)$, employment status $(\mathrm{n}=2$, $0.59 \%)$ and CES-D ( $\mathrm{n}=10,3.20 \%)$, therefore, these cases were excluded from the multiple regression models. The sample size was calculated using $G^{*}$ Power V.3.0.10. ${ }^{60}$ With power of $80 \%$, a 0.05 level of statistical significance, an effect size of $0.15^{61}$ and the number of predictors as 13 , the required sample size for the multiple regression model was calculated as 131 . The level of significance was set at $\mathrm{p}<0.05$. All analyses were performed using IBM SPSS Statistics for Windows V.22.0.

\section{Patient and public involvement}

Patients and/or public were not involved in developing the hypothesis, the aim, nor were they involved in developing plans for study design or implementation of the study.

\section{RESULTS}

In total, 341 questionnaires were returned. Four questionnaires were from participants aged over 65 years or who did not provide their age. We excluded these questionnaires, which left 337 questionnaires for analysis (effective response rate: 98.8\%). Participants' background information (demographic characteristics, individual factors, environmental factors) is shown in table 1. Results are reported below as mean $\pm \mathrm{SD}$.

Participants mean age was $42.8 \pm 11.7$ years. Approximately, $67.7 \%$ were male and $60.2 \%$ were married. $38.6 \%$ lived with their spouse and children, and $22.8 \%$ lived alone. $61.1 \%$ had graduated with a college education or higher, and most participants had regular employment. $83.4 \%$ felt good about their economic status. The mean CES-D score was 12.8 \pm 7.6 , with 99 participants (29.5\%) rated as having depression based on the cut-off point. The mean PSS score was $25.8 \pm 6.2$, with one-quarter of participants being treated for a disease. The mean BMI was $22.0 \pm 3.1 ; 74.8 \%$ of participants were in the healthy range (over 18.5, less than 25). 83.3\% reported their self-rated health as good or fairly good. The mean physical complaint score was $19.3 \pm 5.1$, and mean scores for physical exertion and isometric load were $4.9 \pm 1.8$ and $3.2 \pm 1.3$, respectively. At least $50 \%$ of participants chose most of the healthy lifestyle options, and approximately $75 \%$ chose some health options. The mean PHCS and eHEALS scores were $23.4 \pm 6.5$ and $22.0 \pm 7.5$, respectively. The mean tradition subscale score was $8.0 \pm 1.6$ and that 
Table 1 Background of the participants

\begin{tabular}{|c|c|c|}
\hline Items & $\begin{array}{l}\text { No or } \\
\text { mean } \pm \text { SD }\end{array}$ & $\begin{array}{l}\% \\
\text { (range) }\end{array}$ \\
\hline \multicolumn{3}{|l|}{ Demographic characteristics } \\
\hline Age & $42.8 \pm 11.7$ & $(18-64)$ \\
\hline \multicolumn{3}{|l|}{ Sex } \\
\hline Male & 228 & 67.7 \\
\hline Female & 109 & 32.3 \\
\hline \multicolumn{3}{|l|}{ Marital status } \\
\hline Unmarried & 110 & 32.6 \\
\hline Married & 203 & 60.2 \\
\hline Divorced/widowed & 24 & 7.1 \\
\hline \multicolumn{3}{|l|}{ Household membership } \\
\hline Live alone & 76 & 22.8 \\
\hline Spouse & 48 & 14.4 \\
\hline Spouse and children & 129 & 38.6 \\
\hline Parents & 50 & 15.0 \\
\hline Others & 31 & 9.3 \\
\hline \multicolumn{3}{|l|}{ Educational status } \\
\hline Junior high school/high school & 78 & 23.1 \\
\hline $\begin{array}{l}\text { Vocational college/Junior } \\
\text { college }\end{array}$ & 53 & 15.7 \\
\hline $\begin{array}{l}\text { College or university/graduate } \\
\text { school }\end{array}$ & 206 & 61.1 \\
\hline \multicolumn{3}{|l|}{ Employment status } \\
\hline Full-time worker & 301 & 89.9 \\
\hline Part-time worker & 27 & 8.1 \\
\hline Others & 7 & 2.1 \\
\hline \multicolumn{3}{|l|}{ Economic status } \\
\hline Sufficient & 106 & 31.5 \\
\hline Slightly sufficient & 175 & 51.9 \\
\hline Slightly insufficient & 51 & 15.1 \\
\hline Insufficient & 5 & 1.5 \\
\hline \multicolumn{3}{|l|}{ Depression (CES-D) } \\
\hline Score & $12.8 \pm 7.6$ & $(0-45)$ \\
\hline $\begin{array}{l}\text { Depression (CES-D } \geq 16 \text {; } \\
\text { cut-off point) }\end{array}$ & 99 & 29.5 \\
\hline
\end{tabular}

Dependent variable

\section{Cognitive stress appraisal (PSS) $\quad 25.8 \pm 6.2 \quad(6-48)$}

Disease currently under treatment

\begin{tabular}{lrc} 
No & 252 & 75.0 \\
\hline Yes & 84 & 25.0 \\
\hline High blood pressure & 25 & 7.4 \\
\hline Gout & 11 & 3.3 \\
\hline Hyperlipidaemia & 8 & 2.4 \\
\hline Respiratory disease & 8 & 2.4 \\
\hline Diabetes & 7 & 2.1 \\
\hline Digestive disease & 7 & 2.1 \\
\hline
\end{tabular}

Table 1 Continued

\begin{tabular}{|c|c|c|}
\hline Items & $\begin{array}{l}\text { No or } \\
\text { mean } \pm \text { SD }\end{array}$ & $\begin{array}{l}\% \\
\text { (range) }\end{array}$ \\
\hline Mental disease & 7 & 2.1 \\
\hline Others & 26 & 7.7 \\
\hline \multicolumn{3}{|l|}{ Body mass index (BMI) } \\
\hline Mean & $22.0 \pm 3.1$ & $\begin{array}{l}(14.5- \\
34.6)\end{array}$ \\
\hline Thin $(\mathrm{BMI}<18.5)$ & 32 & 9.8 \\
\hline Standard $(18.5 \leq \mathrm{BMl}<25)$ & 243 & 74.8 \\
\hline Obesity (25 $\mathrm{BMI})$ & 50 & 15.4 \\
\hline \multicolumn{3}{|l|}{ Self-rated health } \\
\hline Very poor & 7 & 2.2 \\
\hline Rather poor & 47 & 14.6 \\
\hline Rather good & 216 & 66.9 \\
\hline Very good & 53 & 16.4 \\
\hline \multicolumn{3}{|c|}{ Brief Job Stress Questionnaire (BJSQ) } \\
\hline Physical complaint & $19.3 \pm 5.1$ & $(11-36)$ \\
\hline \multicolumn{3}{|c|}{ Physical demands (job content: JCQ) } \\
\hline Physical exertion & $4.9 \pm 1.8$ & $(3-11)$ \\
\hline Isometric load & $3.2 \pm 1.3$ & $(2-8)$ \\
\hline \multicolumn{3}{|l|}{ Life style } \\
\hline No smoking & 255 & 75.7 \\
\hline $\begin{array}{l}\text { Non or sometimes drinking } \\
\text { alcohol }\end{array}$ & 256 & 76.0 \\
\hline Breakfast everyday & 241 & 71.5 \\
\hline $\begin{array}{l}\text { More than once a week } \\
\text { physical activity }\end{array}$ & 75 & 22.3 \\
\hline $\begin{array}{l}\text { No eating after dinner over } \\
3 \text { days per week }\end{array}$ & 246 & 73.0 \\
\hline $\begin{array}{l}\text { No skipping breakfast over } \\
3 \text { days per week }\end{array}$ & 248 & 73.6 \\
\hline Get enough sleep and rest & 190 & 56.5 \\
\hline $\begin{array}{l}\text { Perceived health competence } \\
\text { (PHCS) }\end{array}$ & $23.4 \pm 6.5$ & $(8-40)$ \\
\hline eHealth literacy (eHEALS) & $22.0 \pm 7.5$ & $(3-40)$ \\
\hline
\end{tabular}

Environmental factors

\section{Organisational climate}

$\begin{array}{lll}\text { Tradition } & 8.0 \pm 1.6 & (6-12) \\ \text { Organisational environment } & 8.6 \pm 1.8 & (6-12) \\ \text { Social support } & 5.4 \pm 1.2 & (2-7)\end{array}$

CES-D, Centre for Epidemiologic Studies Depression Scale; eHEALS, eHealth Literacy Scale; JCQ, Job Content Questionnaire; PHCS, Perceived Health Competence Scale; PSS, Perceived Stress Scale.

of the organisational environment scale was $8.6 \pm 1.8$. The mean social support scale score was $5.4 \pm 1.2$.

There were correlations among demographic characteristics, individual and environmental factors, and cognitive stress appraisal. Spearman's correlation coefficients 
Table 2 Cognitive stress appraisal and related factors

$\boldsymbol{\beta}$

$P$ values

\begin{tabular}{lll}
\hline $\begin{array}{l}\text { Demographic characteristics } \\
\text { Economic status }\end{array}$ & 0.171 & $<0.001$ \\
$\begin{array}{l}\text { (1=sufficient, } 2 \text { =slightly sufficient, } \\
\text { 3=slightly insufficient, 4=insufficient) }\end{array}$ & & \\
$\begin{array}{l}\text { Individual factors } \\
\text { eHealth literacy (total score) }\end{array}$ & -0.113 & 0.012 \\
$\begin{array}{l}\text { Environmental factors } \\
\begin{array}{l}\text { Organisational climate: tradition } \\
\text { (total score) }\end{array}\end{array}$ & 0.131 & 0.004 \\
$\quad \begin{array}{l}\text { Social support (total score) } \\
\text { Adjusted } \mathrm{R}^{2}\end{array}$ & -0.205 & $<0.001$ \\
\hline
\end{tabular}

Multiple regression analysis.

Controlled variables: age, sex ( $0=$ female, $1=$ male), depression ( $0=$ no, $1=$ yes).

eHealth, electronic health.

were used to measure the linear relationship between each factor and PSS among workers. The demographic characteristics showing significant correlations with cognitive stress appraisal were: age $(r=-0.300, p<0.001)$, marital status $(\mathrm{r}=-0.207, \mathrm{p}<0.001)$, household membership $(\mathrm{r}=-0.231, \mathrm{p}<0.001)$, economic status $(\mathrm{r}=0.355, \mathrm{p}<0.001)$ and depression $(\mathrm{r}=0.528, \mathrm{p}<0.001)$. Individual factors showing significant correlations with cognitive stress appraisal were: self-rated health $(\mathrm{r}=-0.275, \mathrm{p}<0.001)$, physical complaints $(r=0.372, p<0.001)$, total scores for physical exertion $(\mathrm{r}=0.109, \mathrm{p}=0.048)$ and isometric load $(\mathrm{r}=0.183$, $\mathrm{p}=0.001)$, physical activity $(\mathrm{r}=-0.162, \mathrm{p}=0.003)$, sleeping and resting $(\mathrm{r}=-0.278, \mathrm{p}<0.001)$, perceived health competence $(\mathrm{r}=0.412, \mathrm{p}<0.001)$ and eHealth literacy $(\mathrm{r}=-0.295$, $\mathrm{p}<0.001)$. Environmental factors showing significant correlations with cognitive stress appraisal were: total scores for the tradition $(\mathrm{r}=0.197, \mathrm{p}<0.001)$ and organisational environment scales $(r=-0.182, p=0.001)$ and social support $(\mathrm{r}=-0.398, \mathrm{p}<0.001)$.

In the multiple regression analysis, factors associated with cognitive stress appraisal, (marital status, household membership, economic status, physical activity, sleeping, isometric load, eHealth literacy, tradition and organisational environment scales, and social support) were used as independent variables, and age, sex and depression as control variables (table 2). This analysis indicated that those with poorer economic status $(\beta=0.171, \mathrm{p}<0.001)$, lower eHealth literacy $(\beta=-0.113, p=0.012)$, higher traditional organisational climate $(\beta=0.131, p=0.004)$ and lower perceived social support $(\beta=-0.205, p<0.001)$ experienced a higher level of perceived negative stress. The adjusted $R^{2}$ in this analysis was 0.412 .

\section{DISCUSSION}

Participants in this study were representative of healthy adult workers in a range of employment types in Japan. First, in terms of demographic characteristics (eg, age, sex) and proportion of participants, this study was similar to the reported national statistics for full-time workers in Japan. ${ }^{62}$ Second, the PSS scores in this study were similar to those obtained when the PSS was originally developed ${ }^{18}$ and those of adults in other countries. ${ }^{6364}$ Therefore, this study can be generalised to other workers in Japan and to other developed countries.

Our study is the first to examine the features of cognitive stress appraisal in workers and identify associated individual and environmental factors. This study adds to existing research evidence that both individual factors (including eHealth literacy) and environmental factors (such as organisational climate) are related to cognitive stress appraisal among workers. Therefore, this study has important practical implications in promoting stress management and primary prevention of stress-related disease and suicide among workers.

Economic status was related to cognitive stress appraisal. It is possible that poor economic status in itself is the origin of stress, and workers with poor economic status have difficulty coping with their own stress. Cognitive stress appraisal and subjective economic status are related, and self-efficacy plays an important role as a mediator between cognitive evaluation of stress and life satisfaction. ${ }^{65}$ Workers may be unable to appraise challenges and struggle in stressful situations because they feel that their own ability level is low and they have limited resources.

We found that lower eHealth literacy was related to negative stress appraisal. Health literacy is a cognitive and social skill that determines individuals' motivation and ability to gain access to, understand and use information in ways that promote and maintain good health. ${ }^{66}$ Higher health literacy may enable an individual to actively seek support and solutions to problems. ${ }^{67}$ Good eHealth literacy means people can access health information resources via the internet. The internet is increasingly becoming an effective information tool for improving self-care behaviour. ${ }^{68-70}$ In addition, the internet holds a considerable amount of health information, which is helpful for positive cognitive stress appraisal. Improving eHealth literacy may empower workers to obtain, understand and act on information they need for optimal mental health.

We also found that more traditional organisational climates were related to negative cognitive stress appraisal. A traditional organisational climate is more directive and feudalistic. ${ }^{56}$ Higher tradition scores correspond to higher levels of depressive state, lower job satisfaction and lower levels of mental health. ${ }^{56} \mathrm{~A}$ traditional structure or climate implies high levels of mandatory working, a lack of respect for individual opinion and pressure from superiors. Workers in traditional organisational climates have less discretion and a more stressful environment. They may be unable to ask for help from their supervisor, or make improvements to the work environment. The relationship between organisational climate and workers' performance may be explained using the social exchange theory. This theory is based on the assumption that social 
exchanges involve several actions that create obligations, and that relationships evolve over time into trusting, loyal and mutual commitments. ${ }^{71}$ Organisational climate can be changed when employers establish a climate that is perceived as positive by their employees with good relationships, and this can result in better organisational performance and higher levels of motivation in workers.

In addition, lower levels of social support were related to negative stress appraisal. This is consistent with previous studies that reported the amount of social support was associated with levels of depression, ${ }^{72}$ and that social support buffered adverse effects on mental health. ${ }^{73}$ Social support also protects individuals from the pathogenic effects of stressful events by altering the appraisal of those events or the process by which perceived stress causes illness. ${ }^{18}$ Those who feel that they have little social support may be unable to buffer stressful events, whereas those who feel that they have sufficient social support may be able to buffer stressful events.

Our findings suggested that an interprofessional approach involving public health nurses and health practitioners that includes provision of enhanced self-coping skills using individual workers' eHealth literacy, along with development of more modern organisational climates in workplaces and social support in communities may be effective in minimising the effect negative cognitive stress appraisal that may be associated with an increased risk of depression. This would contribute to the overall promotion of mental health among workers.

\section{Limitations}

This study had several limitations. First, we used a cross-sectional design, meaning that we could not identify causal relationships between cognitive stress appraisal and related factors. Second, the response rate was low, which might be explained by the number of instruments included in the questionnaire. Future studies should consider the number of included questions and collection method for questionnaires. Third, the adjusted $R^{2}$ was 0.412 , which was higher than the values of $0.05-0.27$ previously reported. ${ }^{65}$ Although this provides an adequate explanation of factors related to cognitive stress appraisal, other factors are also likely to have contributed. In future, longitudinal studies should be conducted across other areas to widen the scope of investigation.

\section{CONCLUSIONS}

This study examined cognitive stress appraisal and identified factors related to cognitive stress appraisal among workers. The results indicated that cognitive stress appraisal is associated with economic status, depression, eHealth literacy, traditional organisational climates and social support. Therefore, it is recommended that public health nurses and health practitioners enhance eHealth literacy, and improve organisational climates and social support, to help improve depression and support workers to develop better cognitive stress appraisal. Furthermore, occupational and community interventions are required to create and inform people of opportunities for cognitive stress appraisal in the workplace and the community.

Acknowledgements The authors would like to thank all the employees who agreed to participate in this study. We thank Audrey Holmes, MA, from Edanz Group (www.edanzediting.com/ac) for editing a draft of this manuscript.

Contributors NT, ET and AA contributed to develop the concept and design of this study. ET was responsible for acquiring the institutional review board approval of this study. NT was responsible for data collection and analysis. NT and AA were responsible for drafting and revising the manuscript. ET was responsible for study supervision and reporting of study results. All authors read and approved the final manuscript.

Funding This study was supported by University Center of Community (COC) program funded by the Ministry of Education, Culture, Sports, Science and Technology, Japan (http://www.mext.go.jp/en/) (PI:Dr. Etsuko Tadaka).

Competing interests None declared.

Patient consent Not required.

Ethics approval The Institutional Review Board of the Medical Department of the Yokohama City University approved this study on 9 August 2016 (Certification No.A1608008; PI: ET).

Provenance and peer review Not commissioned; externally peer reviewed.

Data sharing statement № additional unpublished data from the study are available at the moment.

Open access This is an open access article distributed in accordance with the Creative Commons Attribution Non Commercial (CC BY-NC 4.0) license, which permits others to distribute, remix, adapt, build upon this work non-commercially, and license their derivative works on different terms, provided the original work is properly cited and the use is non-commercial. See: http://creativecommons.org/ licenses/by-nc/4.0/

(c) Article author(s) (or their employer(s) unless otherwise stated in the text of the article) 2018. All rights reserved. No commercial use is permitted unless otherwise expressly granted.

\section{REFERENCES}

1. World Health Organization [Internet]. Depression. Genéve, 2016. http://www.who.int/mediacentre/factsheets/fs369/en/

2. Ministry of Health, Labor and Welfare [Internet]. Patient survey. Tokyo, 2015. http://www.mhlw.go.jp/toukei/saikin/hw/kanja/14/dl/ kanja.pdf

3. World Health Organization [Internet]. Protecting workers' health. Genéve, 2017. http://www.who.int/mediacentre/factsheets/fs389/en/

4. World Health Organization [Internet]. Comprehensive mental health action plan 2013-2020. Genéve, 2013. http://www.who.int/mental_ health/action_plan_2013/en/

5. World Health Organization [Internet]. Mental Health Action Plan 20132020. Genéve, 2013. http://apps.who.int/iris/bitstream/10665/89966/ 1/9789241506021_eng.pdf?ua $=1$

6. World Economic Forum and the Harvard School of Public Health [Internet]. The global economic burden of non-communicable diseases. Genéve, 2011. http://apps.who.int/medicinedocs/ documents/s18806en/s18806en.pdf

7. van den Berg TI, Alavinia SM, Bredt FJ, et al. The influence of psychosocial factors at work and life style on health and work ability among professional workers. Int Arch Occup Environ Health 2008;81:1029-36.

8. Lee YM. Loss of productivity due to depression among Korean employees. J Occup Health 2010;52:389-94.

9. Kim SE, Kim HN, Cho J, et al. Direct and indirect effects of five factor personality and gender on depressive symptoms mediated by perceived stress. PLoS One 2016;11:e0154140.

10. Ministry of Health, Labor and Welfare [Internet]. Industrial accident compensation insurance for mental disorders. Tokyo, 2011. http:// www.mhlw.go.jp/bunya/roudoukijun/rousaihoken04/dl/120215-01. pdf

11. Ministry of Health, Labor and Welfare [Internet]. Industrial accident compensation insurance for mental disorders. Tokyo, 2016. http:// www.mhlw.go.jp/file/04-Houdouhappyou-11402000-Roudoukijunk yokuroudouhoshoubu-Hoshouka/h27_seishin.pdf 
12. Ministry of Health, Labor and Welfare [Internet]. Basic survey on industrial safety and health. Tokyo, 2013. http://www.mhlw.go.jp/file/ 05-Shingikai-11201000-Roudoukijunkyoku-Soumuka/0000061406. pdf

13. Ministry of Health, Labor and Welfare [Internet]. Stress check system. Tokyo, 2015. http://www.mhlw.go.jp/bunya/roudoukijun/ anzeneisei12/

14. Lazarus R. Psychological stress and the coping process. New York: McGraw-Hill, 1966.

15. Lazarus R, Folkman S. Stress, appraisal, and coping. New York: Springer, 1984

16. Carpenter R. A review of instruments on cognitive appraisal of stress. Arch Psychiatr Nurs 2016;30:271-9.

17. Le Fevre M, Matheny J, Kolt GS. Eustress, distress, and interpretation in occupational stress. Journal of Managerial Psychology 2003;18:726-44.

18. Cohen S, Kamarck T, Mermelstein R. A global measure of perceived stress. J Health Soc Behav 1983;24:385-96.

19. Cohen S, Williamson G. Perceived stress in a probability sample of the United States. In: Spacapan S, Oskamp S, eds. Newbury Park, Calif: SageThe social psychology of health, 1988:31-67.

20. Schelle KJ, Olthof BM, Reintjes W, et al. A survey of substance use for cognitive enhancement by university students in the Netherlands. Front Syst Neurosci 2015;9:10.

21. Roberti JW, Harrington LN, Storch EA. Further psychometric support for the 10-item version of the perceived stress scale. Journal of College Counseling 2006;9:135-47.

22. Hamaideh SH, Al-Ashram SA, Al-Modallal H. Premenstrual syndrome and premenstrual dysphoric disorder among Jordanian women. $J$ Psychiatr Ment Health Nurs 2014;21:60-8.

23. Wawrzyniak AJ, Whiteman MCP. Perceived stress, loneliness, and interaction with fellow students does not affect innate mucosal immunity in first year university students. Jpn Psychol Res 2011;53:121-32.

24. Gupta R, Singh N, Kumar R. Longitudinal predictive validity of emotional intelligence on first year medical students perceived stress. BMC Med Educ 2017;17:139.

25. Li S, Li L, Zhu X, et al. Comparison of characteristics of anxiety sensitivity across career stages and its relationship with nursing stress among female nurses in Hunan, China. BMJ Open 2016;6:e010829.

26. Györffy Z, Girasek E. Mental health of physicians-nationwide representative study from hungary. Ideggyogy Sz 2015;68:258-69.

27. Su X, Lau JT, Mak WW, et al. Development of the perceived stress scale for people living with HIV/AIDS in China. AIDS Patient Care STDS 2008:22:989-98.

28. Kimura T, Yokoyama A, Kohno N, et al. Perceived stress, severity of asthma, and quality of life in young adults with asthma. Allergol Int 2009;58:71-9.

29. Hara $\mathrm{Y}$, Hisatomi $\mathrm{M}$, Ito $\mathrm{H}$, et al. Effects of gender, age, family support, and treatment on perceived stress and coping of patients with type 2 diabetes mellitus. Biopsychosoc Med 2014;8:16.

30. Lee EH, Chung BY, Suh $\mathrm{CH}$, et al. Korean versions of the Perceived Stress Scale (PSS-14, 10 and 4): psychometric evaluation in patients with chronic disease. Scand J Caring Sci 2015;29:183-92.

31. Mitchell AM, Crane PA, Kim Y. Perceived stress in survivors of suicide: psychometric properties of the perceived stress scale. Res Nurs Health 2008;31:576-85.

32. Andreou E, Alexopoulos EC, Lionis C, et al. Perceived stress scale: reliability and validity study in Greece. Int J Environ Res Public Health 2011;8:3287-98.

33. Barrington WE, Ceballos RM, Bishop SK, et al. Perceived stress, behavior, and body mass index among adults participating in a worksite obesity prevention program, Seattle, 2005-2007. Prev Chronic Dis 2012;9:E152.

34. Leung DY, Lam TH, Chan SS. Three versions of perceived stress scale: validation in a sample of Chinese cardiac patients who smoke. BMC Public Health 2010;10:513.

35. Willert MV, Wieclaw J, Thulstrup AM. Rehabilitation of individuals on long-term sick leave due to sustained stress-related symptoms: a comparative follow-up study. Scand J Public Health 2014;42:719-27.

36. Wiernik E, Nabi H, Pannier B, et al. Perceived stress, sex and occupational status interact to increase the risk of future high blood pressure: the IPC cohort study. J Hypertens 2014;32:1979-86.

37. Horiuchi S, Tsuda A, Kim E, et al. Relationships between stage of change for stress management behavior and perceived stress and coping. Jpn Psychol Res 2010;52:291-7.

38. Hoover DS, Vidrine JI, Shete S, et al. Health Literacy, smoking, and health indicators in african american adults. $J$ Health Commun 2015;20(Suppl 2):24-33.
39. Faresjö Å, Theodorsson E, Chatziarzenis M, et al. Higher perceived stress but lower cortisol levels found among young Greek adults living in a stressful social environment in comparison with Swedish young adults. PLoS One 2013;8:e73828.

40. Mimura C, Griffiths P. A Japanese version of the perceived stress scale: translation and preliminary test. Int J Nurs Stud 2004;41:379-85.

41. Mimura C, Griffiths P. A Japanese version of the perceived stress scale: cross-cultural translation and equivalence assessment. BMC Psychiatry 2008;8:85.

42. Shima S, Kano T, Kitamura T, et al. Atarashii yokuutsusei jiko hyouka syakudo ni tsuite (A new self-report depression scale). Clinical Psychiatry 1985;27:717-23

43. Radloff LS. The CES-D Scale. A self-report depression scale for research in the general population. Applied Psychological Measurement 1985;1:385-401.

44. Shimomitsu T, Odagiri Y. The brief job stress questionnaire. Japanese Journal of Occupational Mental Health 2004;12:25-36.

45. Kawakami N, Fujigaki Y. Reliability and validity of the Japanese version of Job Content Questionnaire: replication and extension in computer company employees. Ind Health 1996;34:295-306

46. Karasek R, Brisson C, Kawakami N, et al. The Job Content Questionnaire (JCQ): an instrument for internationally comparative assessments of psychosocial job characteristics. J Occup Health Psychol 1998;3:322-55.

47. Kawakami N, Kobayashi F, Araki S, et al. Assessment of job stress dimensions based on the job demands- control model of employees of telecommunication and electric power companies in Japan: reliability and validity of the Japanese version of the Job Content Questionnaire. Int J Behav Med 1995;2:358-75.

48. Suzuki-Saito T. [Medical care costs and the characteristics of higher medical costs among BMI groups in the early-stage elderly analysis of data obtained from a large-scale study of 29,490 elderly]. Nihon Koshu Eisei Zasshi 2012;59:466-73.

49. Togari T, Yamazaki Y, Koide S, et al. [Reliability and validity of the modified Perceived Health Competence Scale (PHCS) Japanese version]. Nihon Koshu Eisei Zasshi 2006;53:51-7.

50. Leon-Perez JM, Antino M, Leon-Rubio JM. The role of psychological capital and intragroup conflict on employees' burnout and quality of service: a multilevel approach. Front Psychol 2016;7:7.

51. Smith MS, Wallston KA, Smith CA. The development and validation of the Perceived Health Competence Scale. Health Educ Res 1995; 10:51-64.

52. Mitsutake S, Shibata A, Ishii K, et al. [Developing Japanese version of the eHealth Literacy Scale (eHEALS)]. Nihon Koshu Eisei Zasshi 2011;58:361-71.

53. Norman CD, Skinner HA. eHealth literacy: essential skills for consumer health in a networked world. J Med Internet Res 2006;8:e9.

54. Norman CD, Skinner HA. eHEALS: The eHealth Literacy Scale. $J$ Med Internet Res 2006;8:e27.

55. Ministry of Internal Affairs and Communications [Internet]. White paper on information and communications in Japan. Tokyo, 2016. http://www.soumu.go.jp/johotsusintokei/whitepaper/eng/WP2016/ chapter-5.pdf\#page $=1$

56. Fukui S, Haratani T, Toshima Y, et al. Measuring workplace climate: reliability and validity of the 12-item Organizational Climate Scale (OCS-12). Sangyo Eiseigaku Zasshi 2004;46:213-22.

57. Hemingway MA, Smith CS. Organizational climate and occupational stressors as predictors of withdrawal behaviours and injuries in nurses. Journal of Occupational and Organizational Psychology 1999;72:285-99.

58. Iwasa $\mathrm{H}$, Gondo H, Masui $\mathrm{Y}$, et al. Reliability and validity of "Social Support Scale", Japanese language edition: Investigation targeting middle and old age. Indicators of Social Welfare 2007;54:26-33

59. Zimet GD, Dahlem NW, Zimet SG, et al. The multidemensional scale of perceived social support. J Pers Assess 1988;52:30-41.

60. Faul F, Erdfelder E, Lang AG, et al. G*Power 3: a flexible statistical power analysis program for the social, behavioral, and biomedical sciences. Behav Res Methods 2007;39:175-91.

61. Cohen J. A power primer. Psychol Bull 1992;112:155-9.

62. Japan Institute for Labour Policy and Training [Internet]. Labour statistics data. Tokyo, 2016. http://www.jil.go.jp/kokunai/statistics/ timeseries/html/g0209.html

63. Katsarou A, Panagiotakos D, Zafeiropoulou A, et al. Validation of a Greek version of PSS-14; a global measure of perceived stress. Cent Eur J Public Health 2012;20:104-9.

64. Remor E. Psychometric Properties of a European Spanish Version of the Perceived Stress Scale (PSS). Span J Psychol 2006;9:86-93. 
65. Lee J, Kim E, Wachholtz A. The effect of perceived stress on life satisfaction: The mediating effect of self-efficacy. Chongsonyonhak Yongu 2016;23:29-47.

66. NUTBEAM DON. Health promotion glossary. Health Promot Int 1986;1:113-27.

67. Ishikawa $\mathrm{H}$, Nomura $\mathrm{K}$, Sato $\mathrm{M}$, et al. Developing a measure of communicative and critical health literacy: a pilot study of Japanese office workers. Health Promot Int 2008;23:269-74.

68. Ministry of Economy, Trade and Industry [Internet]. Employment status survey. Tokyo, 2012. http://www.stat.go.jp/english/data/ shugyou/pdf/sum2012.pdf

69. Ritterband LM, Palermo TM. Introduction to the special issue: eHealth in pediatric psychology. J Pediatr Psychol 2009;34:453-6.
70. Mitsutake S, Shibata A, Ishii K, et al. Associations of eHealth literacy with health behavior among adult internet users. $J$ Med Internet Res 2016;18:e192.

71. Cropanzano R, Mitchell MS. Social Exchange Theory: An Interdisciplinary Review. J Manage 2005;31:874-900.

72. Koizumi Y, Awata S, Kuriyama S, et al. Association between social support and depression status in the elderly: results of a 1-year community-based prospective cohort study in Japan. Psychiatry Clin Neurosci 2005;59:563-9.

73. Frasure-Smith N, Lespérance F, Gravel G, et al. Social support, depression, and mortality during the first year after myocardial infarction. Circulation 2000;101:1919-24. 